\title{
AC 2007-906: INTRADISCIPLINARY TEACHING IN THE ENGINEERING STUDIES CURRICULUM: APPLYING NUMERICAL MODELING TECHNIQUES TO STATICS PROBLEMS
}

\section{Wayne Johnson, Armstrong Atlantic State University}

Wayne Johnson is currently an Assistant Professor in Engineering Studies at Armstrong Atlantic State University in Savannah, GA. He recently received his Ph. D. in mechanical engineering from Georgia Tech. His current research interests include mechatronics, vibrations and engineering education.

\section{Priya Goeser, Armstrong Atlantic State University}

Priya T. Goeser is currently an Assistant Professor of Engineering Studies at Armstrong Atlantic State University, Savannah, GA. She received her Ph.D. in mechanical engineering from the University of Delaware in 2001. Her current research interests are finite element modeling, functionally graded materials and engineering education. 


\title{
Intradisciplinary Teaching in the Engineering Studies Curriculum: Applying Numerical Modeling Techniques to Statics Problems
}

\begin{abstract}
Students often view the classes in the Engineering Studies curriculum at Armstrong Atlantic State University as being a set of discrete and disconnected courses. This misunderstanding leads to a struggle to retain and apply course concepts from one class to subsequent classes. This work attempts to address this issue by the development of an intradisciplinary teaching and learning effort across a Statics and Computational Modeling course. The approach employed the use of specific problem examples from the Statics course (ENGR 2001) adapted for use in the Computational Modeling course (ENGR 2010). These are two of the core courses taken by mechanical and civil engineers during their sophomore year. The Statics course presents the principles of statics including equilibrium of rigid bodies, analysis of truss systems, shear and bending moment diagrams, and the calculation of centroids and center of mass. Emphasis is also placed on teaching the students to analyze problems in a systematic and logical manner. The main objective of the Computational Modeling course is to study the fundamentals of numerical methods and to develop computer programs for solving engineering problems using MATLAB. Examples of numerical methods include solving roots of equations, linear algebraic equations, integration and differentiation. Assessment of this effort was accomplished with supplementary course evaluation questions given at the end of the semester. This paper will discuss the results of the student projects and evaluations, and the authors' experiences with this intradisciplinary teaching effort.
\end{abstract}

\section{Introduction}

This paper presents efforts over two semesters to integrate course materials between two sophomore level engineering courses. The two courses, Statics (ENGR 2001) and Computational Modeling (ENGR 2010), are usually taken concurrently by mechanical and civil engineering students in the fall semester. Both courses can be considered the students' first "real" engineering courses after their first calculus-based physics course. The ultimate goal of this effort is knowledge transfer between courses within a discipline. For example, if the student is faced with an engineering design problem that could benefit from using tools from multiple courses, they will recall and correctly implement those tools to obtain a solution.

The Engineering Studies Program at Armstrong Atlantic State University (AASU) is part of a regional engineering program in which students complete their initial two years at AASU and then transfer to Georgia Tech to complete their engineering degrees. The program enrollment is approximately 215 students with 70 of those declared as mechanical or civil engineering majors.

There has been much work in the area of interdisciplinary teaching and learning. Interdisciplinary teaching involves specific efforts to apply knowledge and concepts to multiple academic disciplines simultaneously. Many courses combining knowledge from various areas have been established including nanodevices and public policy ${ }^{1}$, petroleum engineering and business management ${ }^{2}$ and multidisciplinary capstone senior design projects ${ }^{3,4}$. In addition to interdisciplinary curricula, several multidisciplinary departments and schools have been 
established, most notably, biomedical engineering, civil and environmental engineering, and mechatronics engineering. However, intradisciplinary teaching and learning has not received as much attention.

Intradisciplinary teaching involves a specific effort to apply knowledge and concepts within a single discipline simultaneously. Ruocco and Dixon ${ }^{5}$ presented a teaching model for a multidisciplinary and intradisciplinary engineering design team. The intradisciplinary component of the design team consisted of team members from lower and upper level courses within the same discipline. Other than Ruocco and Dixon's work, intradisciplinary teaching and learning is rarely discussed in the literature. It is thought that the reason for such limited discussion on this concept is due to its assumed inclusion in engineering curricula. This is likely to be the case to some extent, for example, the co-author teaching the Computational Modeling course always included example problems based on engineering applications. However, there was previously no effort to promote the use computational modeling techniques in applicable courses taught concurrently. The authors perceived this as a missed opportunity to reinforce intradisciplinary learning or knowledge transfer early in the engineering curriculum. In the absence of these efforts, students may not be exposed to these knowledge transfer requirements for problem solving until their senior level courses. The use of MATLAB in a Statics course is not new. For example, Al-Masoud ${ }^{6}$ used a graphical user interface for solving and visualization of various statics problems including vector operations, 2 and 3-D equilibrium, trusses, and shear and bending moment diagrams. There is also a supplement to the Statics course textbook titled "Solving Statics Problems in Matlab" . However, the examples do not fully embrace the techniques used in the Computational Modeling course.

In the following sections, we present a more detailed description of the Statics and Computational Modeling courses, examples of course integration, assessment, and conclusions of our experiences.

\section{Statics}

Statics is offered every semester at AASU. This effort was implemented in the Fall 2005 and Fall 2006 semesters since Computation Modeling is only offered in the fall semesters. The prerequisites for Statics are Calculus II and Physics I. There is also a co-requisite for Calculus III (vector-based). The curriculum for Statics presents the principles of equilibrium of a variety of systems including single rigid bodies, trusses, frames, machines, and beams. A key goal of the course is to train the students in solving problems in a systematic and logical manner.

After completing Statics students are expected to be able to:

- Describe position, forces and moments in terms of their vector components in two and three dimensions

- Select appropriate reference coordinate axes, draw free body diagrams, and understand the relation between constraints imposed by supports and forces acting on the body

- Formulate static equilibrium equations for a rigid body and evaluate member forces in trusses, frames, and machines

- Apply Coulomb's dry friction laws to engineering problems

- Calculate centroids and moments of inertia 
- Draw shear and bending moment diagrams

Students are introduced to many of the stated learning outcomes for Statics in the physics course. However, the concepts are presented in more detail in Statics with solutions to more complex problems.

\section{Computational Modeling}

Computational Modeling is a sophomore course taken primarily by mechanical and civil engineering students. The prerequisites for Computational Modeling are Calculus II, Physics I and an introductory 3 -credit course in programming. The course covers the following topics: Mathematical and Computational Modeling, Introduction to MATLAB, and Error Analysis; Roots of Equations; Linear Algebraic Equations; Curve Fitting and Interpolation; Numerical Differentiation and Integration and Ordinary Differential Equations. The introductory 3-credit course in programming - Computing for Engineers using MATLAB (ENGR 1371) covers programming fundamentals such as scripts, vectors, conditional statements, iteration, functions, arrays and matrices, structures, strings, recursion; and procedural programming techniques such as plotting, file I/O, images, sound, fundamental numerical methods and sorting. This course ensures that the students are familiar with MATLAB prior to taking the Statics and Computational Modeling courses.

All topics are covered using a combination of lectures, written assignments and computer projects. The students study in detail the concepts behind the numerical methods commonly used by engineers including the advantages and disadvantages of various methods. The application of error analysis in order to check accuracy of results is emphasized. These methods are then developed into computer programs using MATLAB. The students learn to use relevant built-in functions within the software as well as write their own functions. Emphasis is placed on writing user-friendly, time and memory efficient computer programs. In order to gain experience in practical problem solving, examples from various engineering disciplines including civil engineering, mechanical engineering and electrical engineering are used.

After completing Computational Modeling, students are expected to be able to:

- Formulate a problem,

- Select the best solution approach,

- Analyze it using computational modeling,

- Perform an error analysis, and

- Communicate the results in a user-friendly, written and graphical form.

\section{Course Integration Examples}

Four projects were selected for the course integration effort. The problems from the first three projects were first presented as example problems in the Statics course. In subsequent weeks, these problems were modified to utilize computational modeling techniques and presented as projects to the students in the Computational Modeling course. The students worked in groups of two on these projects. 
The first problem was taken from the Statics course textbook ${ }^{8}$. Based on Figure 1, the students developed a MATLAB program to study the variation in $\mathrm{M}_{0}$ due to $\mathrm{T}=120 \mathrm{lbs}$ as the position of point $\mathrm{B}$ varies from $(0,0,0)$ to $(0,14,0)$. Figure 2 shows a plot of the variation in the $\mathrm{x}, \mathrm{y}$ and $\mathrm{z}$ components of $\mathrm{M}_{0}$ vs. the $\mathrm{y}$-coordinate of point $\mathrm{B}$.

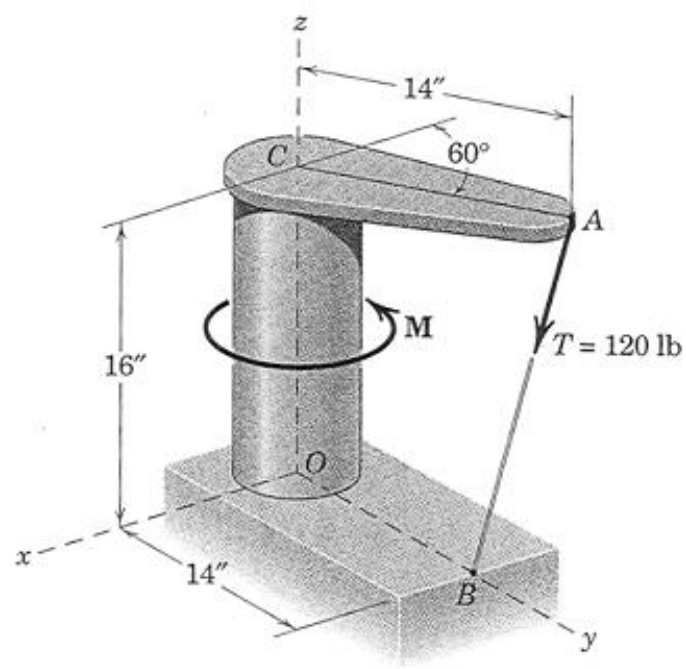

Figure 1. Variation of moment problem taken from Meriam and Kraige ${ }^{8}$

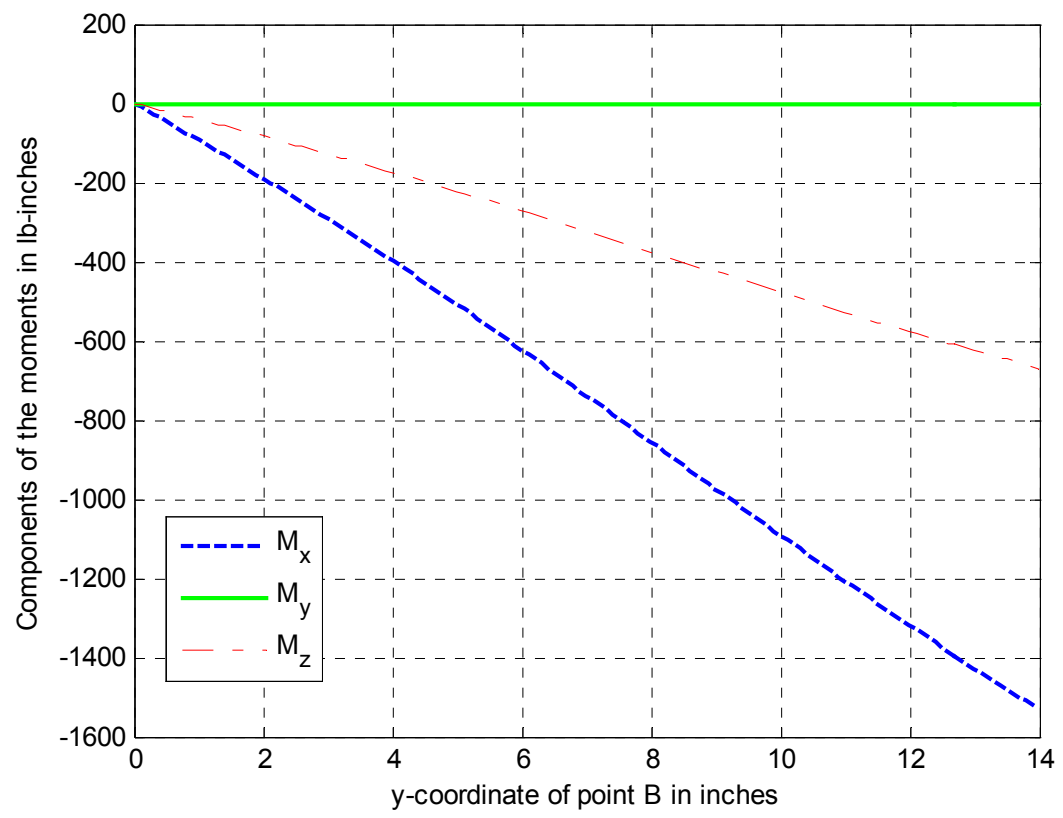

Figure 2. Plot of Mo with variation in attachment point.

The solution to the problem required the use of iteration, functions for vector operations such as norm.m and cross.m, and various plotting utilities in MATLAB. Most students were able to 
complete this problem without much help from the instructor in both Fall 2005 and Fall 2006 semesters.

The second project was a space truss problem shown in Figure 3 adapted from Riley and Sturges ${ }^{9}$. The students were asked to write a MATLAB function to calculate a unit vector $\boldsymbol{n}$ based on two points $A$ and $B$ in space. The desired output is a unit vector oriented along the direction $A$ to $B$. This function was also used in another MATLAB program to study the variation in the support reactions with the angle $\theta$ (angle the applied load P makes with the zaxis) at each of the joints: A, B and C. It is given that the angle $\theta$ varies from $-90^{\circ}$ to $90^{\circ}$.

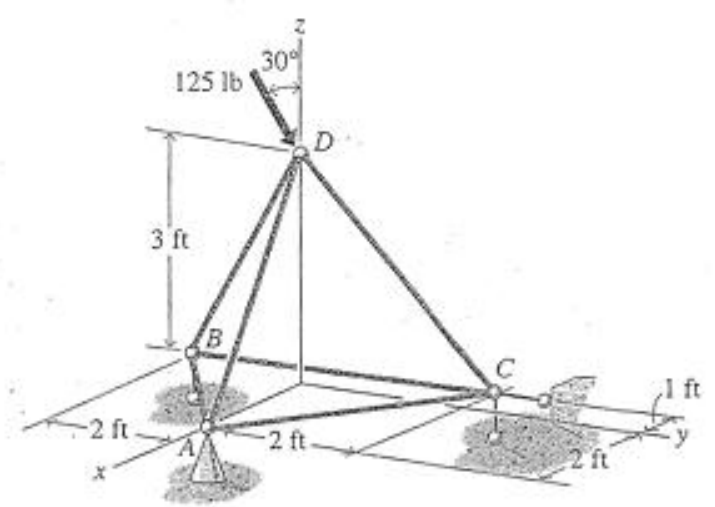

Fig. $7-43$

Figure 3. Space truss problem from Riley and Sturges 9

The solution to this problem required solving iteratively at each value of $\theta$, a set of linear algebraic equations at each joint using the Gauss elimination procedure. A representative plot of the results is shown in Figure 4. Class discussions of the results emphasized the utility of this approach in a design scenario where certain values of reactionary forces are desired with a varying applied load orientation. 


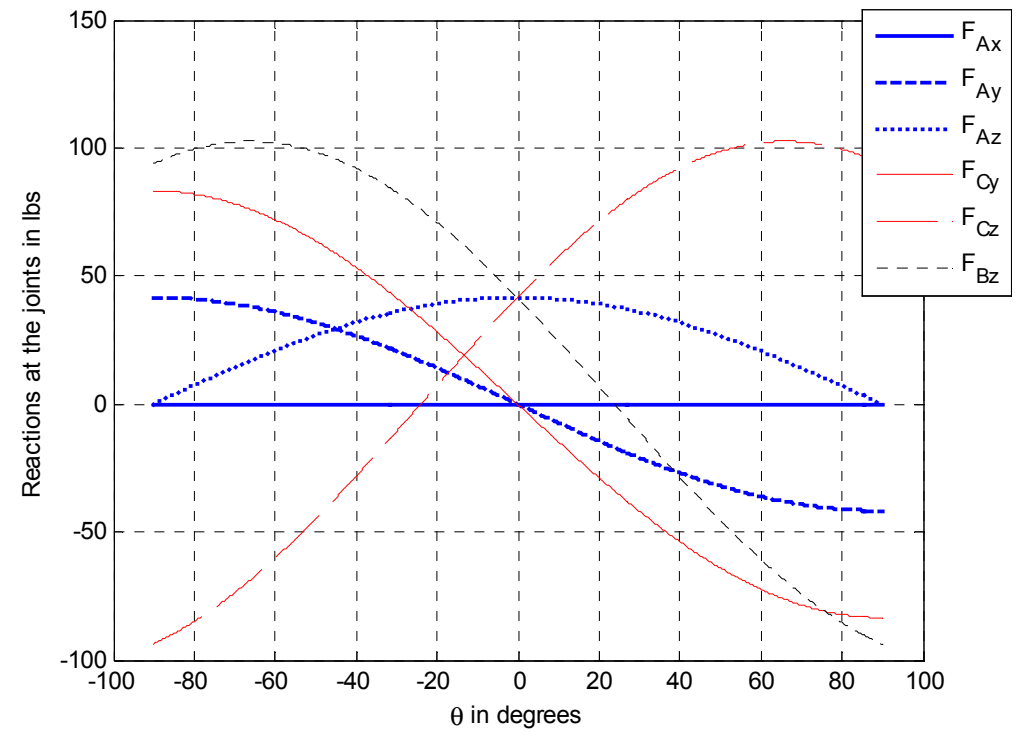

Figure 4. Variation of reaction forces with the direction of the applied load.

A few of the students struggled to grasp the concept of solving a set of three linear algebraic equations at each of the four joints for each value of $\theta$ from $-90^{\circ}$ to $90^{\circ}$. In the Fall 2005 semester, the instructor provided them with a sample program as a starting point. Once they completed the project with or without the sample program, they appreciated the use of the program to perform the otherwise time-consuming, repetitious computations for them. It should be noted here that the sample program was not provided in the Fall 2006 semester, but most students were able to successfully complete the problem.

The third project consisted of two centroid calculation problems. The students utilized numerical integration techniques to solve these problems. The students completed this project without any problems in both semesters.

The final intradiscipinary problem given utilized numerical integration techniques to determine the relative deflection of the wing tip on a Boeing 747-400 aircraft based on the lift forces acting on the wing at cruising altitude $(35,000 \mathrm{ft})$. The students were given an idealized lift force as a load per unit length expressed as the function $\mathrm{w}(\mathrm{x})$ :

$$
w(x)=w_{0}\left(1-\left(\frac{x}{L}\right)^{2}\right)^{1 / 2}
$$

where $\mathrm{L}$ is the length of the wing and $\mathrm{w}_{\mathrm{o}}=5000 \mathrm{lbs} / \mathrm{ft}$.

They were also provided with the expression,

$$
E I \frac{d^{2} y}{d x^{2}}=M(x)
$$

where $\mathrm{E}$ is the modulus of elasticity, I is the second moment of the cross-sectional area, $\mathrm{y}(\mathrm{x})$ is the beam deflection function, and $\mathrm{M}(\mathrm{x})$ is the bending moment function. Equation 2 relates the 
deflection of a beam to the bending moment. Equation 2 is not discussed in the Statics course; however, the relationships between bending moment $\mathrm{M}(\mathrm{x})$, shear force $\mathrm{V}(\mathrm{x})$, and distributed loads $\mathrm{w}(\mathrm{x})$ are covered in detail in Statics. This provides a sufficient framework for the application of statics concepts and self-discovery of the necessary relationships to relate the bending moment to the deflection of the wing. Figure 5 shows the variation of bending moment and shear force and Figure 6 illustrates the wing deflection along its length.

This project was used in the Fall 2006 semester only. It involved the use of several numerical methods such as numerical integration, curvefitting, ordinary differential equations and the graphical representation of the results. By this time in the semester, students are fairly proficient with programming in MATLAB and are familiar with the common numerical methods necessary for problem solving. Hence, it was not surprising that most of the students completed the project successfully and in creative ways. For instance, this is a complex problem and there are several different ways of solving for the deflection in the wing. It was interesting to see the different groups use different methods to find the best solution approach.
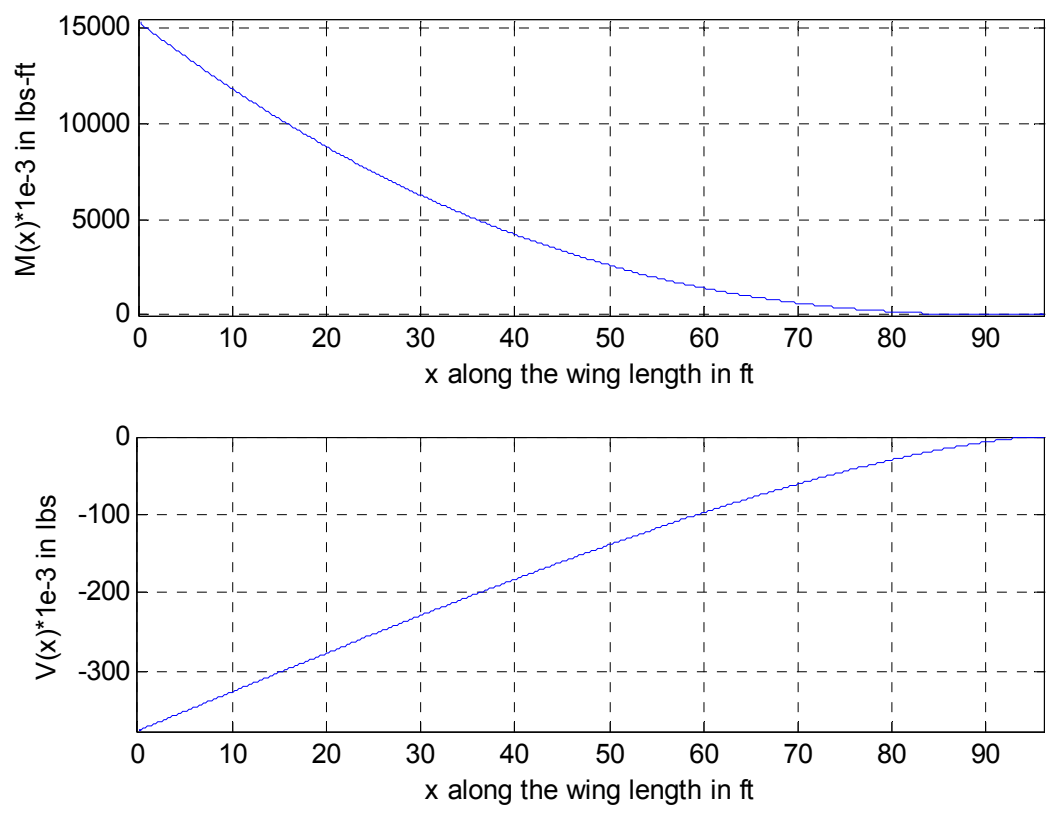

Figure 5. Variation of the bending moment and shear force along the length of the wing. 


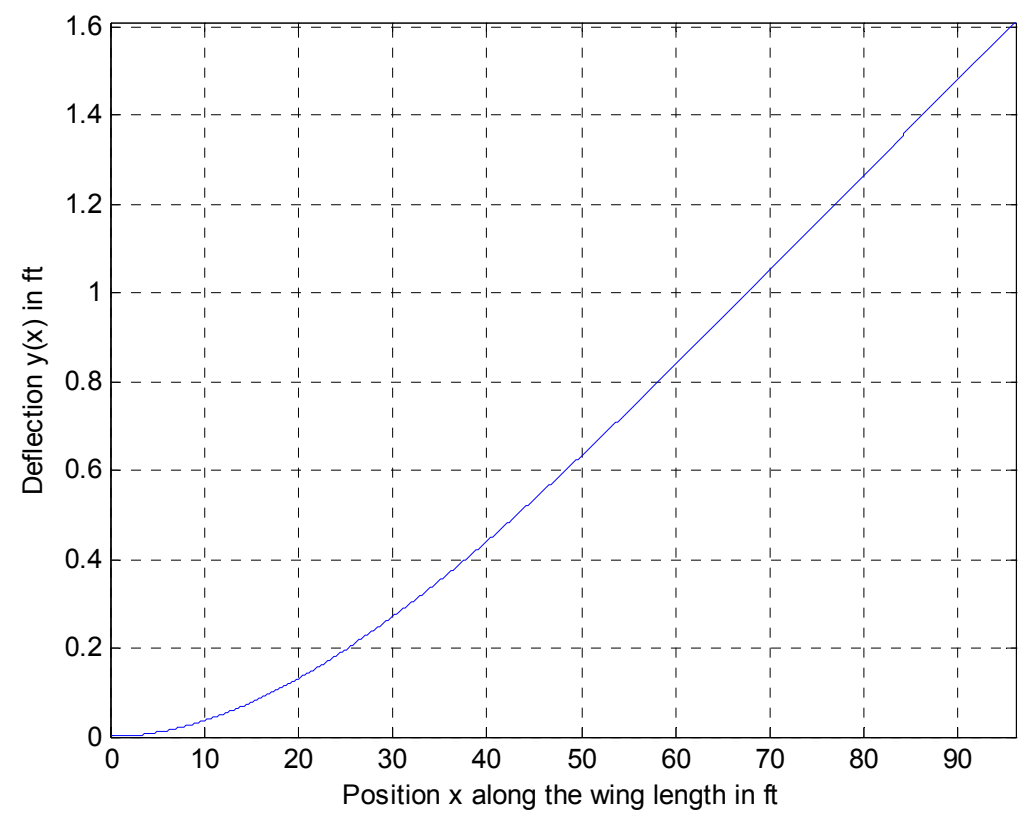

Figure 6. Variation of wing deflection along the length of the wing.

\section{Assessment}

Assessment of this effort was accomplished via supplementary survey questions given with the Faculty and Course Evaluations (FACE) at the end of the semester. The results of the student evaluations and the authors' experiences on the intradisciplinary teaching effort are discussed in this section.

Table 1 shows the survey questions and results from the Fall 2005 and Fall 2006 semesters. The surveys were given to the students in the Computational Modeling course.

\begin{tabular}{|l|l|c|c|}
\hline \multicolumn{1}{|c|}{ Questions } & \multicolumn{1}{|c|}{ Options } & \multicolumn{1}{|c|}{$\begin{array}{c}\text { Fall 2005 } \\
(\mathrm{N}=10)\end{array}$} & $\begin{array}{c}\text { Fall 2006 } \\
(\mathrm{N}=9)\end{array}$ \\
\hline Using statics examples in ENGR 2010 & Strongly Agree & $70 \%$ & $22 \%$ \\
improved my understanding of the & Agree & $30 \%$ & $67 \%$ \\
application of computational modeling & Disagree & $0 \%$ & $11 \%$ \\
concepts. & Strongly Disagree & $0 \%$ & $0 \%$ \\
& Not Applicable & $0 \%$ & $0 \%$ \\
\hline I am more likely to retain information from & Strongly Agree & $50 \%$ & $22 \%$ \\
ENGR 2201 based on the intradisciplinary & Agree & $40 \%$ & $56 \%$ \\
problems given. & Disagree & $0 \%$ & $22 \%$ \\
& Strongly Disagree & $0 \%$ & $0 \%$ \\
& Not Applicable & $10 \%$ & $0 \%$ \\
\hline I am more likely to retain information from & Strongly Agree & $70 \%$ & $44 \%$ \\
\hline
\end{tabular}




\begin{tabular}{|c|c|c|c|}
\hline $\begin{array}{l}\text { ENGR } 2010 \text { based on the intradisciplinary } \\
\text { problems given. }\end{array}$ & $\begin{array}{l}\text { Agree } \\
\text { Disagree } \\
\text { Strongly Disagree } \\
\text { Not Applicable }\end{array}$ & $\begin{array}{l}30 \% \\
0 \% \\
0 \% \\
0 \%\end{array}$ & $\begin{array}{l}56 \% \\
0 \% \\
0 \% \\
0 \%\end{array}$ \\
\hline $\begin{array}{l}\text { This intradisciplinary teaching approach } \\
\text { should be continued in subsequent semesters. }\end{array}$ & $\begin{array}{l}\text { Strongly Agree } \\
\text { Agree } \\
\text { Disagree } \\
\text { Strongly Disagree } \\
\text { Not Applicable }\end{array}$ & $\begin{array}{c}80 \% \\
20 \% \\
0 \% \\
0 \% \\
0 \%\end{array}$ & $\begin{array}{c}44 \% \\
56 \% \\
0 \% \\
0 \% \\
0 \%\end{array}$ \\
\hline
\end{tabular}

Table 1. Survey questions and results from the Fall 2005 and Fall 2006 semesters.

$\mathrm{N}$ is the sample size.

Written comments from the students included:

- "Definitely helps me apply MATLAB to certain courses by doing relative examples.";

- "The intradisciplinary agenda between classes is a very good idea. It brings all the skills together from different classes for good practice.";

- "I enjoyed doing statics problems using MATLAB to do the computation!";

- "Using problems relevant to civil engineering helped me understand MATLAB and be able to use it in other classes." and

- "Shows the use of some of the programs we use."

The results of the surveys and the student comments show success in this teaching approach. In addition to benefits such as a better understanding of the concepts, retention of information, enthusiasm for learning, etc. among the students, the students also used the concepts of computational modeling and MATLAB in other courses. For example, in a case study project for the sophomore engineering course - Introduction to Engineering Materials (ENGR 2000), one of the teams used computational modeling using MATLAB to predict fatigue failure for an automobile axle. In yet another sophomore engineering course - Dynamics (ENGR 2202), a few of the students used MATLAB to solve a differential equation to find the angular velocity of a bar attached via a pin joint within a metal block. In both these courses, the students were not required to use MATLAB.

As a part of the assessment, the authors would also like to mention that some students did encounter problems/struggles because of this approach. A few student comments from the surveys support this: "Material would have been received better if MATLAB exposure was better prior to introducing statics topic."; and "Simpler problems should be used as it is hard trying to learn two things at one time." These comments show that students are not familiar with using concepts from one course in another and vice-versa.

As mentioned in the section on course integration examples, the problems from the first three projects were first presented as example problems in the Statics course. In subsequent weeks, these problems were modified to utilize computational modeling techniques and presented as 
projects to the students in the Computational Modeling course. Also, in the current curriculum, all engineering students will take either a one-credit course - Computing in MATLAB (ENGR 1171 ) in addition to the 3-credit programming course (CSCI 1301) or a 3-credit course Computing for Engineers using MATLAB (ENGR 1371); prior to both the Statics and Computational Modeling courses. This will ensure that all students will be familiar with MATLAB and hence address the above concerns.

The development of the course integration problems initially required several brief meetings between the authors over the Fall 2005 semester. However in the following year, it was only necessary to coordinate the timing of the projects given in the Computational Modeling course with the relevant topics covered in the Statics course. The most vital aspect in the successful implementation of this effort was communication between the instructors. This effort can be replicated at other institutions with similar curricula.

\section{Conclusions}

The results of intradisciplinary teaching using a Computational Modeling and Statics course were presented. These efforts can be reasonably replicated with other courses with moderate collaboration between faculty members. Although our sample size is small, our survey results indicate that these efforts should be continued in subsequent semesters.

Since most of the students who took the Statics and Computational Modeling courses in the Fall 2006 semester will be taking Dynamics (ENGR 2202) in the Spring 2007 semester, we plan to further assess our intradisciplinary efforts by assigning problems requiring the use of computational modeling tools in the Dynamics course. However, they will not be specifically instructed to use these tools to obtain a solution. In addition, computational modeling techniques will be used to solve problems in the Fundamentals of Thermodynamics (ENGR 3322) course, which will also be taught in the Spring 2007 semester.

\section{Bibliography}

1. Isaacs, J., et al. Engineering and Public Policy at the Nanoscale: An Interdisciplinary Graduate Course. in Proceedings of the 2006 ASEE Annual Conference \& Exposition. 2006. Chicago, IL: American Society for Engineering Education.

2. Abbott, D., et al. Development and presentation of the interdisciplinary course Petroleum Project Evaluation: integrating entrepreneurial and business concepts into a petroleum engineering curriculum. in Proceedings of the 2006 ASEE Annual Conference \& Exposition. 2006. Chicago IL: American Society for Engineering Education.

3. Probst, D.K. A Proposed Interdisciplinary Senior Capstone Course. in Proceedings of the 2002 Annual ASEE Conference \& Exposition. 2002. Montréal, Canada.

4. Stone, R.B. and N. Hubing. Striking a Balance: Bringing Engineering Disciplines Together for a Senior Design Sequence. in Proceedings of the 2002 Annual ASEE Conference \& Exposition. 2002. Montréal, Canada: American Society for Engineering Education. 
5. Ruocco, A.S. and R.S. Dixon. A Multidisciplinary Capstone Teaching Model - An Integrated, Multilevel, Intradisciplinary Engineering Design Approach. in in Proceedings of the 27th Annual Frontiers in Education Conference. 1997. Pittsburgh, PA: IEEE.

6. $\quad$ Al-Masoud, N. Integrating MATLAB Graphical User Interface in Statics Course. in 2006 ASEE Conference and Exposition. 2006. Chicago, IL: American Society for Engineering Education.

7. Harper, B.D., Solving Statics Problems in MATLAB. 2002, New York: John Wiley \& Sons, Inc.

8. Kraige, L.G. and J.L. Meriam, Engineering Mechanics: Statics. 5 ed. 2002, New York: John Wiley \& Sons, Inc.

9. Riley, W.F. and L.D. Sturges, Engineering Mechanics: Statics. 2 ed. 1996, New York: John Wiley \& Sons, Inc. 